\title{
FEMINICÍDIO: UMA LEITURA A PARTIR DA PERSPECTIVA FEMINISTA
}

\section{Resumo}

Com este trabalho, pretendo formular um olhar sobre o fenômeno do feminicídio a partir das categorias de análise da diferença e hierarquia, entendidas no âmbito dos estudos feministas, tendo como motivação inicial o debate jurídico sobre a pertinência de legislação específica e sua efetividade na reversão das condições que motivam a violência contra as mulheres.

Palavras-chave: feminicídio, violência de gênero, mulher, hierarquia, diferença.

\section{Abstract}

\section{Femicide: a reading from feminist look}

The aim of this study is to formulate an approach on the femicide phenomenon from the analysis of the categories of difference and hierarchy, understood in the context of feminist studies, having as initial motivation the legal debate about the relevance of specific legislation and its effectiveness in reversing the conditions that motivate violence against women.

Keywords: feminicide, gender violence, woman, hierarchy, difference.

\section{Resumen}

\section{Feminicidio: una lectura fundada en la perspectiva feminista.}

El objetivo de este estudio es formular un enfoque del fenómeno del feminicidio basado en las categorías de análisis de diferencia y jerarquía, entendidas en el contexto de los estudios feministas, con referencia inicial al debate jurídico sobre la relevancia de la legislación específica y su eficacia en la inversión de las condiciones que motivan la violencia contra las mujeres.

Palabras clave: feminicidio, violencia de género, mujer, jerarquía, diferencia.

\section{1. $O$ contexto}

As Nações Unidas definem este termo [feminicídio] como «o assassinato de mulheres por serem-no». É uma das mais sangrentas e visíveis [formas de violência]. Geral-

Núcleo de Estudos e Pesquisa sobre Identidade do Programa de Estudos Pós Graduados em Serviço Social, Pontifícia Universidade Católica de São Paulo, Perdizes - São Paulo - SP, CEP: 05014-901, Brasil.

Endereço eletrónico: tate.adv@uol.com.br

Endereço Postal: Rua Manuel Gonçalves Foz, 1-A, Perdizes, São Paulo-SP, Brasil, CEP 05009-010. 
mente é precedido por violência sexual e outros atos que ameaçam a dignidade das mulheres, tanto por agressores conhecidos como desconhecidos (Agatón 2013, s.p.).

Existem criminosos que afirmam impassíveis: «Eu a matei porque ela era minha». Assim, sem mais, como se fosse coisa do senso comum e de toda a justiça e direito de propriedade privada, que torna o homem dono da mulher. Mas nenhum, nenhum, nem mesmo o mais macho dos supermachos tem a coragem de confessar: «Eu a matei por medo», porque ao fim e ao cabo o medo da mulher à violência do homem é o espelho do medo do homem à mulher sem medo. ${ }^{1}$

A afirmação de Isabel Agatón abre espaço para a necessidade de explicitar o feminicídio, seus contornos, enquanto forma específica de violência contra as mulheres, e de encontrar as motivações que transformam um aparente episódio extremo de conflito doméstico num fenômeno que se assemelha a outros processos de exterminação seletiva de seres humanos.

Tal como o «genocídio», o termo «feminicídio» remete para a ocorrência de processos com ampla incidência, para padrões de procedimentos, motivados por interesses concretos e em contextos temporais e territoriais definidos.

Também, tal como «genocídio», o feminicídio agrega diversos mecanismos de violação de direitos e da dignidade humana que, mesmo não culminando na morte da mulher, deixam marcas que a afetam para a vida. Nas palavras de Marcela Lagarde:

A categoria feminicídio é parte da base teórica feminista. Desenvolvi-a a partir da obra de Diana Russell e Jill Radford, apresentada em seu texto Femicide. The politics of woman killing (1992). A tradução de é femicídio.

Mudei de para o feminicídio, porque em espanhol é termo homólogo e só significa homicídio e assassinato de mulheres. As referidas autoras definem o feminicídio como um crime de ódio contra as mulheres, como todas as formas de violência que por vezes terminam em assassinato e até mesmo suicídio.

Identifico um problema mais por tais crimes se estenderem no tempo: a ausência ou fraqueza do Estado de Direito, na qual se reproduzem a violência ilimitada e assassinatos sem castigo. Então, para diferenciar os termos, preferi o termo feminicídio e assim designar o conjunto de crimes contra a humanidade que consistem em atos criminosos, sequestros e desaparecimentos de meninas e mulheres em um contexto de colapso institucional. É uma fratura do Estado de direito que favorece a impunidade. Por isso eu digo que feminicídio é um crime de Estado. Deve ser esclarecido que existe feminicídio em condições de guerra e paz. (in Espósito 2011, s.p.).

1 Este texto de Eduardo Galeano foi escrito como introdução à canção «Nunca más a mi lado», do grupo «No Te Va Gostar - NTVG», que integrou uma campanha contra a violência doméstica no Uruguai, em 2011. Disponível em https: / / www.youtube.com/watch?v=KXw9KBioVz4. 
Também as palavras de Eduardo Galeano apontam para um quadro de dominação patriarcal onde a diferenciação do gênero decorre em formulações hierárquicas dos valores e dos direitos entre homens e mulheres ao ponto de determinar a apropriação do direito sobre a vida da mulher.

O termo feminicídio começou a ganhar relevância em função do alarme sobre crimes contra meninas e mulheres nas cidades de Juarez e Chihuahua, no México, a partir de 1993. Após o horror e consternação iniciais, surgiu a denúncia e a demanda por justiça, que, no entanto, não corresponderam a respostas satisfatórias por parte das autoridades, quer quanto às motivações, quer em relação aos autores das práticas violentas e sistemáticas sobre as mulheres. Surgiram organizações de apoio às famílias das vítimas e de luta contra a violência contra as mulheres, bem como grupos de apoio às vítimas que reuniram alguns movimentos civis em defesa dos direitos humanos e movimentos de mulheres e feministas. Todavia, os assassinatos associados às práticas simultâneas de tortura e violação sexual continuaram e as reivindicações locais para o esclarecimento dos crimes e dos desaparecimentos de mulheres estenderam-se ao âmbito nacional. Desde então, Ciudad Juarez é conhecida no mundo pelos crimes de meninas e mulheres, através de campanhas para diminuir a impunidade que os acompanharam.

O tema do feminicídio transcendeu a fronteira mexicana por meio de organizações diretamente ligadas às instituições de justiça e dos movimentos de mulheres. Estas organizações têm recorrido a organizações internacionais civis e institucionais, como a Amnistia Internacional, a Corte Interamericana de Direitos Humanos, o Parlamento Europeu, e o Congresso dos Estados Unidos, os municípios de cidades de vários países, ONG, redes de mulheres e outros, com o intuito de denunciar as ocorrências e exigir ações concretas de apuramento e responsabilização das práticas violentas.

O México recebeu, numa década, mais de 50 recomendações internacionais e relatores de vários órgãos da ONU e de direitos humanos, convocando o governo a esclarecer todos os casos, obter acesso à justiça pelas famílias das vítimas e a implementação de políticas de governo com uma perspectiva de gênero para enfrentar esses crimes e suas causas e erradicar a violência contra as mulheres e a impunidade.

Persiste, todavia, um «enigma» sobre Juarez e Chihuahua: tratando-se, indubitavelmente, de prática de extermínio seletivo - desaparecimento ou rapto, com tortura, violação sexual, quase sempre seguida de morte, de mulheres jovens, trabalhadoras e pobres - não se antevê uma motivação clara e imediata na desproporcional estatística de mulheres assassinadas e desaparecidas. Não sendo inéditas, as práticas sistemáticas e intensivas de violação de direitos, de submissão, de escravidão, exploração sexual, mutilação sexual e extermínio de mulheres em diversos locais do mundo e, normalmente, circunscritos a territórios em conflito e a grupos sociais associados a estruturas culturais conhecidas, são perceptíveis, nesses contextos, as motivações, os seus autores, e os objetivos de tais práticas. No caso de Juarez e Chihuahua, são ainda desconhecidos os 
motivos claros, e os autores, que levaram à morte de 379 meninas e mulheres entre os anos de 1993 a 2005.

Alega-se, naquele contexto, a intenção, por parte das organizações de tráfico de drogas que procuram dominar política, social e economicamente as regiões de fronteira com os Estados Unidos da América - dominado naquela região por fábricas de peças mecânicas que alimentam outras indústrias no mundo - de instalar um clima de terror, coibindo as mulheres de ingressarem no mercado de trabalho e, assim, de adquirirem certa autonomia de sustento, procurando libertar-se, por consequência, dos esquemas de dependência daqueles grupos. Todavia, os processos violentos utilizados, a quantidade de vítimas e a continuidade das práticas e, sobretudo, a sua impunidade, indicia o enraizamento de valores e de representações sociais entre os homens que conduzem a comportamentos discriminatórios e de dominação sobre as mulheres.

Se o uso do termo «feminicídio» se consubstanciou, durante algum tempo, naqueles factos, entretanto ele vem adquirindo maior amplitude de ocorrências, configurando-se como o conjunto de práticas de extrema violência associadas a contextos generalizados de ódio e de discriminação sobre as mulheres, não apenas decorrentes das diferenças e conflitos de gênero, mas da própria condição de existência de ser mulher. Nesse sentido, o feminicídio ocorre não por motivos circunstanciais que poderiam advir de comportamentos misóginos, discriminatórios e de submissão da mulher em face das representações de dominação do patriarcado, mas, sim, devido a uma postura generalizada que perpassa o universo das instituições. O cenário de feminicídio perpetua-se através das práticas violentas e disseminadas sobre a mulher, na impunidade, na cumplicidade do poder público e na ausência de políticas de permitam preveni-lo e combatê-lo.

No entanto, ao contrário do que por vezes se pretende escamotear nos índices da violência, o feminicídio não é uma faceta da violência generalizada que, por acaso, também atinge as mulheres. Tal como questionaram Cameron e Frazer:

quando uma sociedade enfrenta cotidianamente o assassinato de mulheres, não tem sentido perguntar por quê que um indivíduo mata o outro, mas indagar por que é que os membros de alguns grupos matam os membros de outros grupos. Para responder, torna-se necessário relacionar os motivos das práticas violentas com seus sujeitos e sobrepô-los às estruturas sociais e às diferenças de poder fundadas nas hierarquias geradas nas hierarquias do poder sexual (Cameron e Frazer 1987, 30). ${ }^{2}$

O feminicídio apresenta-se como o culminar de um processo continuado de práticas de dominação e submissão sobre as mulheres, onde, a cada violação de direitos e de ofensa à dignidade, se sucedem outras violações. A este processo corresponde a perda de referenciais na relação entre sujeitos, onde a desigual-

2 Tradução da autora. 
dade de poder entre eles resulta na submissão reiterada e sistemática e na perda de direitos dos dominados ao ponto da depreciação do seu direito à vida.

Sendo necessária alguma precaução metodológica na análise dos dados sobre o assassinato de mulheres, dado que, por vezes, as informações e os registros de dados são pouco detalhados ou encobertos, é, contudo, perceptível um padrão de crescimento de casos de feminicídio que se ocultam, por exemplo, entre os casos classificados de violência doméstica.

De acordo com os dados apresentados no Mapa da Violência 2015 - Homicídio de Mulheres do Brasil (Gráfico 1), as taxas de homicídios de mulheres, para além de crescerem de forma acentuada entre 1980 e 1997, tendo alguma reversão até ao ano de 2007, revelam um aumento até ao ano de 2013, mesmo apesar da entrada em vigor da Lei Maria da Penha, em 2006. ${ }^{3}$

\section{Gráfico 1}

Evolução das taxas de homicídio de mulheres. Brasil, 1980-2013

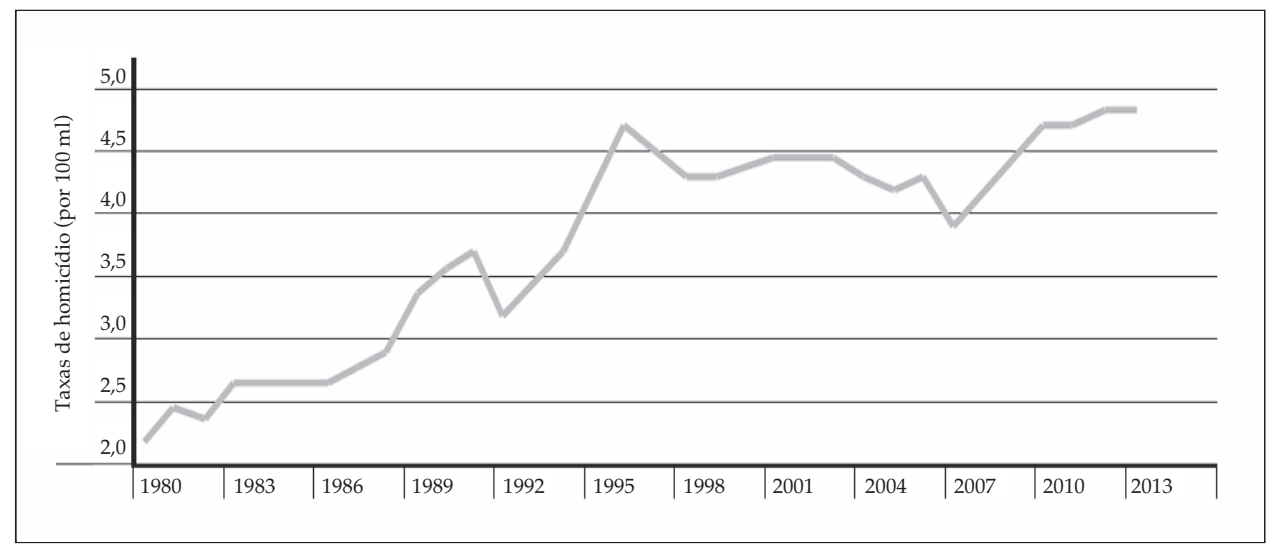

Fonte: Waiselfisz (2015).

Se o crescimento dos denominados homicídios de mulheres acompanha a tendência geral dos homicídios e, de um modo geral, as práticas de violência contra pessoas, há que observar a distribuição das ocorrências de práticas violentas considerando a natureza do agressor - conhecido ou desconhecido -, a incidência

3 A Lei Maria da Penha visa incrementar e destacar o rigor das punições para os crimes decorrentes de violência contra a mulher. Conforme a introdução do texto aprovado, a Lei «Cria mecanismos para coibir a violência doméstica e familiar contra a mulher, nos termos do art. 226 da Constituição Federal, da Convenção sobre a Eliminação de Todas as Formas de Discriminação contra as Mulheres e da Convenção Interamericana para Prevenir, Punir e Erradicar a Violência contra a Mulher; dispõe sobre a criação dos Juizados de Violência Doméstica e Familiar contra a Mulher; altera o Código de Processo Penal, o Código Penal e a Lei de Execução Penal; e dá outras providências». 
Gráfico 2

Evolução das taxas de homicídio de mulheres. Brasil, 2003-2013

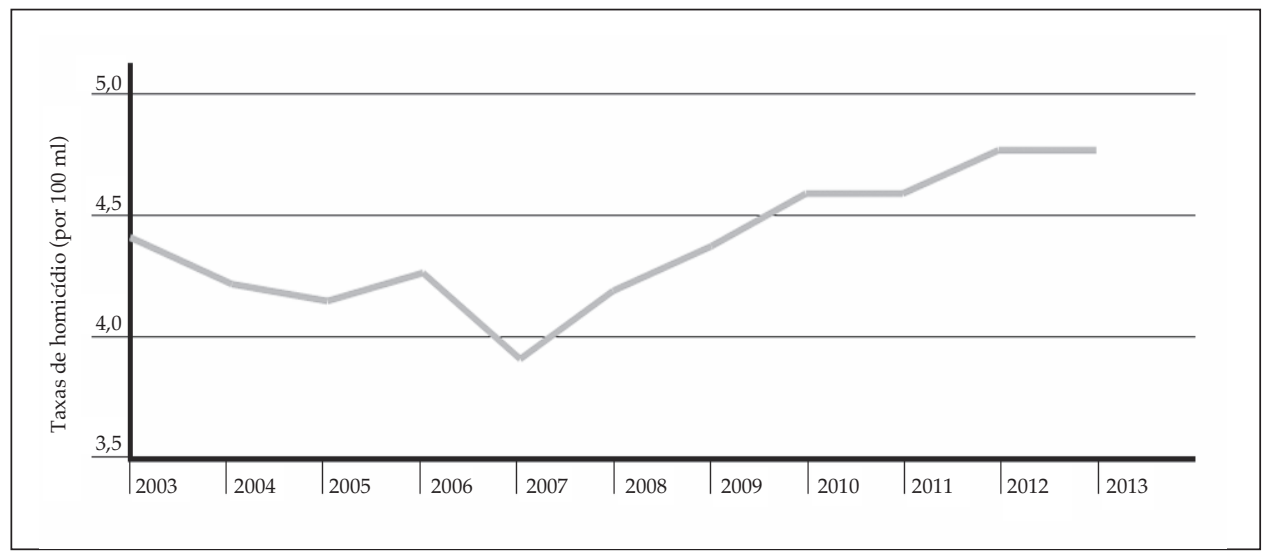

Fonte: Waiselfisz (2015).

Tabela 1

Estrutura de atendimentos de mulheres pelo SUS, ${ }^{4}$ segundo agressor e etapa do ciclo de vida. Brasil, 2014

\begin{tabular}{|c|c|c|c|c|c|c|c|c|c|c|c|c|}
\hline \multirow{2}{*}{ Agressor } & \multicolumn{2}{|c|}{ Criança } & \multicolumn{2}{|c|}{ Adolescente } & \multicolumn{2}{|c|}{ Jovem } & \multicolumn{2}{|c|}{ Adulta } & \multicolumn{2}{|c|}{ Idosa } & \multicolumn{2}{|c|}{ Total } \\
\hline & N. ${ }^{\circ}$ & $\%$ & N. ${ }^{\circ}$ & $\%$ & N. ${ }^{o}$ & $\%$ & N. ${ }^{\circ}$ & $\%$ & N. ${ }^{o}$ & $\%$ & N. ${ }^{\circ}$ & $\%$ \\
\hline Pai & 4758 & 22,7 & 2633 & 9,6 & 476 & 1,4 & 272 & 0,6 & 18 & 0,3 & 8157 & 6,0 \\
\hline Mãe & 6849 & 32,7 & 2694 & 9,8 & 438 & 1,3 & 248 & 0,5 & 52 & 0,8 & 10281 & 7,5 \\
\hline Padrasto & 1576 & 7,5 & 1273 & 4,6 & 292 & 0,9 & 83 & 0,2 & 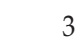 & 0,0 & 3227 & 2,4 \\
\hline Madrasta & 81 & 0,4 & 0 & 0,0 & 0 & 0,0 & 0 & 0,0 & 0 & 0,0 & 81 & 0,1 \\
\hline Cônjuge & 0 & 0,0 & 2095 & 7,6 & 9947 & 29,3 & 15913 & 33,8 & 813 & 12,8 & 28768 & 21,2 \\
\hline Ex-cônjuge & 0 & 0,0 & 565 & 2,1 & 4174 & 12,3 & 5236 & 11, & 106 & 1,7 & 10081 & 7,4 \\
\hline Namorado & 0 & 0,0 & 2405 & 8,7 & 1597 & 4,7 & 1352 & 2,9 & 32 & 0,5 & 5386 & 4,0 \\
\hline Ex-namorado & 0 & 0,0 & 729 & 2,6 & 1250 & 3,6 & 913 & 1,9 & 30 & 0,5 & 2922 & 2,2 \\
\hline Filho & 0 & 0,0 & 62 & 0,2 & 99 & 0,3 & 1910 & 4,1 & 2206 & 34,8 & 4277 & 3,1 \\
\hline Irmão & 875 & 4,2 & 3421 & 12,4 & 3902 & 11,5 & 3982 & 8,5 & 445 & 7,0 & 12625 & 9,3 \\
\hline $\begin{array}{l}\text { Amigo/ } \\
\text { / conhecido }\end{array}$ & 488 & 2,3 & 748 & 2,7 & 1037 & 3,1 & 1049 & 2,9 & 176 & 2,0 & 3798 & 2,8 \\
\hline Desconhecido & 2523 & 12,0 & 5257 & 19,1 & 3732 & 11,0 & 4554 & 9,7 & 485 & 7,7 & 16551 & 12,2 \\
\hline Cuidador & 275 & 1,3 & 71 & 0,3 & 29 & 0,1 & 49 & 0,1 & 216 & 3,4 & 640 & 0,5 \\
\hline Outros & 3499 & 16,6 & 5602 & 20,3 & 6966 & 20,5 & 11158 & 23,7 & 1748 & 27,6 & 28973 & 21,3 \\
\hline Total & 20924 & 100,0 & 27555 & 100,0 & 33939 & 100,0 & 47019 & 100,0 & 6330 & 100,0 & 135767 & 100,0 \\
\hline
\end{tabular}

Fonte: Waiselfisz (2015).

4 SUS - Sistema Único de Saúde. 
no grupo etário das vítimas de violência, o tipo de violência praticado e as taxas de reincidência e a frequência das agressões.

\section{Tabela 2}

Estrutura de atendimentos de mulheres pelo SUS, segundo o tipo de violência e a etapa do ciclo de vida. Brasil, 2014

\begin{tabular}{|c|c|c|c|c|c|c|c|c|c|c|c|c|}
\hline \multirow{2}{*}{$\begin{array}{c}\text { Tipo de } \\
\text { violência }\end{array}$} & \multicolumn{2}{|c|}{ Criança } & \multicolumn{2}{|c|}{ Adolescente } & \multicolumn{2}{|c|}{ Jovem } & \multicolumn{2}{|c|}{ Adulta } & \multicolumn{2}{|c|}{ Idosa } & \multicolumn{2}{|c|}{ Total } \\
\hline & $\mathrm{N} .{ }^{0}$ & $\%$ & ${ }^{\circ}$ & $\%$ & N. ${ }^{o}$ & $\%$ & N. ${ }^{\circ}$ & $\%$ & $\mathrm{~N} .{ }^{\circ}$ & $\%$ & J. ${ }^{\circ}$ & $\%$ \\
\hline ica & 6020 & 22,0 & 611 & 40,9 & 30461 & 58,9 & 406 & 57,1 & 3684 & 38,2 & 96429 & 48,7 \\
\hline 0 & 4242 & 15,5 & 190 & 18,9 & 12701 & 24,5 & 18968 & 26,7 & 2383 & 4,7 & 45484 & 23,0 \\
\hline rtura & 402 & 1,5 & 779 & 2,0 & 1177 & 2,3 & 1704 & 4 & 202 & 1 & 4264 & 2,2 \\
\hline ual & 7920 & 29,0 & 9256 & 24,3 & 3183 & 6,2 & 3044 & 4,3 & 227 & 4 & 23630 & 11,9 \\
\hline & 20 & 0,1 & 16 & 0,0 & 28 & 0,1 & 30 & 0,0 & 3 & 0,0 & 97 & 0,0 \\
\hline , & 115 & 0,4 & - & 0,3 & 477 & 0,9 & 1118 & 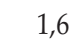 & 601 & 2 & 2433 & 1,2 \\
\hline & 7732 & 28,3 & 2577 & 6,8 & 436 & 08 & 593 & 0,8 & 1837 & 19,0 & 13175 & 6,7 \\
\hline & 14 & 0,5 & 133 & 0,4 & & 0,0 & & 0 & & , & 273 & 0,1 \\
\hline & 7 & 0,3 & 94 & 0,2 & 64 & 0,1 & 90 & 1 & 29 & 0,3 & 352 & 0,2 \\
\hline & 649 & 2,4 & 2359 & 6,2 & 3228 & 2 & 4978 & 0 & 684 & 7,1 & 11898 & 6,0 \\
\hline otal & 27315 & 100,0 & 38137 & 100,0 & 51755 & 100,0 & 71178 & 100,0 & 9650 & 100,0 & 198035 & 100,0 \\
\hline
\end{tabular}

Fonte: Waiselfisz (2015).

Os dados assinalados nas tabelas anteriores denotam um padrão de condutas e de comportamentos por parte dos agressores, maioritariamente conhecidos e de relacionamento próximo das vítimas - pais, cônjuges ou parceiros -, tendo como alvo sobretudo as mulheres jovens e adultas, evidenciando «hábitos» de relações conflituosas e assimétricas que culminam no exercício da violência sobre as mulheres dentro de suas casas (ver tabela 3, 4 e 5).

A elevada incidência dessas práticas sobre mulheres adolescentes e jovens revela que se trata quer de rotinas violentas que se geram no âmbito do ambiente familiar por desgaste das relações matrimoniais, quer de ocorrências no início das relações afetivas e que tendem a desdobrar-se e a persistir no decorrer dos relacionamentos. Este cenário, somado à reincidência de agressões sobre as mulheres, aponta para uma apetência assimilada nos homens para se relacionarem de forma violenta com as mulheres, e para uma condição de sistemática agressão de mulheres em contextos de relação conhecidos.

Tal como adverte Diana Russel (1992), o feminicídio revela-se nesse contínuo terror que inclui uma ampla variedade de abusos verbais e físicos, como a violação, a tortura, o abuso sexual infantil e incestuoso, e a negação de sustento para as 
Tabela 3

Estrutura de atendimentos por violência pelo SUS, segundo a etapa do ciclo de vida e o local de ocorrência. Brasil, 2014

\begin{tabular}{|c|c|c|c|c|c|c|c|c|c|c|c|c|}
\hline \multirow{2}{*}{ Local } & \multicolumn{2}{|c|}{ Criança } & \multicolumn{2}{|c|}{ Adolescente } & \multicolumn{2}{|c|}{ Jovem } & \multicolumn{2}{|c|}{ Adulta } & \multicolumn{2}{|c|}{ Idosa } & \multicolumn{2}{|c|}{ Total } \\
\hline & N. ${ }^{o}$ & $\%$ & N. ${ }^{\circ}$ & $\%$ & N. ${ }^{o}$ & $\%$ & N. ${ }^{\circ}$ & $\%$ & N. ${ }^{o}$ & $\%$ & N. ${ }^{o}$ & $\%$ \\
\hline Residência & 13561 & 75,5 & 13503 & 64,0 & 24594 & 67,9 & 34666 & 75,3 & 5274 & 86,2 & 91598 & 71,9 \\
\hline Escola & 622 & 3,5 & 1002 & 4,7 & 206 & 0,6 & 240 & 0,5 & 6 & 0,1 & 2076 & 1,6 \\
\hline Bar & 72 & 0,4 & 289 & 1,4 & 1023 & 2,8 & 1130 & 2,5 & 32 & 0,5 & 2546 & 2,0 \\
\hline Rua & 1192 & 6,6 & 4153 & 19,7 & 7533 & 20,8 & 6971 & 15,1 & 447 & 7,3 & 20296 & 15,9 \\
\hline $\begin{array}{l}\text { Comercio/ } \\
\text { /Serviços }\end{array}$ & 390 & 2,2 & 264 & 1,3 & 665 & 1,8 & 794 & 1,7 & 60 & 1,0 & 2173 & 1,7 \\
\hline Outros & 2123 & 11,8 & 1886 & 8,9 & 2209 & 6,1 & 2234 & 4,9 & 298 & 4,9 & 8750 & 6,9 \\
\hline Total & 17960 & 100,0 & 21097 & 100,0 & 36230 & 100,0 & 46035 & 100,0 & 6117 & 100,0 & 127439 & 100,0 \\
\hline
\end{tabular}

Fonte: Waiselfisz (2015).

\section{Tabela 4}

Estrutura de atendimentos por violência pelo SUS, segundo a etapa do ciclo de vida e a reincidência da agressão. Brasil, 2014

\begin{tabular}{|c|c|c|c|c|c|c|c|c|c|c|c|c|}
\hline \multirow{2}{*}{ Residência } & \multicolumn{2}{|c|}{ Criança } & \multicolumn{2}{|c|}{ Adolescente } & \multicolumn{2}{|c|}{ Jovem } & \multicolumn{2}{|c|}{ Adulta } & \multicolumn{2}{|c|}{ Idosa } & \multicolumn{2}{|c|}{ Total } \\
\hline & N. ${ }^{\circ}$ & $\%$ & N. ${ }^{\circ}$ & $\%$ & N. ${ }^{\circ}$ & $\%$ & J. ${ }^{\circ}$ & $\%$ & $\mathrm{~V}_{0}$ & $\%$ & $\mathrm{~N} .^{\circ}$ & $\%$ \\
\hline & 6001 & 46, & 7840 & 42,9 & 1442 & 46,3 & 21289 & 54,1 & 2892 & 60,4 & 52445 & 49,2 \\
\hline$\tilde{\tilde{n}}$ & 6988 & 53,8 & 10430 & 57,1 & 16705 & 53,7 & 18039 & 45,9 & 1896 & 39,6 & 54058 & 50,8 \\
\hline otal & 12989 & 100,0 & 18270 & 100,0 & 31128 & 100,0 & 39328 & 100,0 & 4788 & 100,0 & 106503 & 100,0 \\
\hline
\end{tabular}

Fonte: Waiselfisz (2015).

\section{Tabela 5}

Tipo de violência mais grave cometida por pessoa conhecida, segundo a faixa etária da vítima. Brasil, 2014

\begin{tabular}{|c|c|c|c|c|c|c|c|c|}
\hline \multirow{2}{*}{ Residência } & \multicolumn{2}{|c|}{ 18-29 anos } & \multicolumn{2}{|c|}{ 30-59 anos } & \multicolumn{2}{|c|}{$60 \mathrm{e}+$ anos } & \multicolumn{2}{|c|}{ Total } \\
\hline & N. ${ }^{\circ}$ & $\%$ & N. ${ }^{\circ}$ & $\%$ & N. ${ }^{o}$ & $\%$ & N. ${ }^{o}$ & $\%$ \\
\hline Física & 446003 & 55,8 & 572015 & 39,2 & 30382 & 17,5 & 1048400 & 43,1 \\
\hline Sexual & 4964 & 0,7 & 7333 & 0,5 & 753 & 0,4 & 13050 & 0,5 \\
\hline Psicológica & 287181 & 35,9 & 746959 & 51,1 & 130019 & 75,0 & 1164159 & 47,8 \\
\hline Outros & 61088 & 7,6 & 134890 & 9,2 & 12279 & 7,1 & 208257 & 8,6 \\
\hline Total & 799236 & 100,0 & 1461197 & 100,0 & 173433 & 100,0 & 2433866 & 100,0 \\
\hline
\end{tabular}

Fonte: Waiselfisz (2015). 
mulheres. Entendidos isoladamente podem diluir-se na violência cotidiana, mas representam, numa leitura articulada, práticas sistemáticas e reiteradas que se conjugam em contextos de ódio e represália generalizada sobre as mulheres.

Aquele cenário estatístico, relativo aos dados colhidos entre 2013 e 2014, abre espaço à discussão e reflexão sobre a efetividade dos instrumentos, nomeadamente os de natureza jurídica e da política pública, no enfrentamento da tendência crescente de práticas violentas sobre as mulheres, bem como quanto ao papel dos estudos feministas na adequada configuração da situação da mulher no âmbito das relações e representações sociais, considerando as categorias de análise diferença e hierarquia.

\section{O debate jurídico}

É este cenário, aliado ao aumento significativo da taxa de homicídios de mulheres no Brasil a partir de 2007, que leva o poder público a, em março de 2015, sancionar a Lei 13 104/2015, a Lei do Feminicídio, classificando-o como crime hediondo e com agravantes quando acontece em situações específicas de vulnerabilidade - gravidez, menor de idade, na presença de filhos, entre outras.

Do ponto de vista jurídico, não se tratou de uma iniciativa legislativa sem críticas nem isenta de aceso debate. Não existindo, nos argumentos contra a publicação da Lei do Feminicídio, a negação da persistência de contextos de dominação, discriminação e submissão e trato violento sobre as mulheres, alegase que o dispositivo legal, ao penalizar severamente o homicídio contra a mulher, fragiliza os mecanismos de busca pela igualdade e combate à discriminação ao estabelecer diferenciação no trato do crime entre homens e mulheres. No argumento de Yarochewsky:

E é justamente neste ponto que reside um dos problemas do referido projeto. Ao tratar de forma diferenciada a mulher - punindo com mais severidade o homicídio praticado contra a mesma -, numa clara demonstração de discriminação em que a mulher é, em uma visão paternalista, disposta como o sexo frágil, o projeto, também, viola o princípio constitucional da igualdade entre pessoas do mesmo sexo.

Apesar de ser compreensível e até louvável toda a preocupação em combater e reduzir a violência contra a mulher, a aprovação do referido projeto representa um retrocesso na busca pela igualdade e no próprio combate à discriminação, quer seja por sexo, cor ou religião.

Com bem salienta a doutora Nadine Gasmanm, as «Mulheres são pessoas livres e iguais em dignidade e em direitos, donas de seus corpos e de suas expressões e merecem respeito, em toda e qualquer condição. Ao ser signatário de acordos internacionais como a Convenção sobre a Eliminação de Todas as Formas de Discriminação contra as Mulheres (CEDAW), a Convenção Interamericana para Prevenir, Punir e Erradicar a Violência contra a Mulher e a Plataforma de Ação de Pequim, o Brasil 
tem como compromisso trabalhar para que a igualdade de gênero e o empoderamento das mulheres se manifeste em números e na prática».

[...]

Ao tratar o homicídio perpetrado contra mulher (feminicídio) mais severamente do que o cometido contra o homem, o projeto está dizendo que a vida da mulher vale mais que a do homem. Está tratando bens jurídicos idênticos (vida humana) de maneira desigual. Isto, além de violar a Constituição, pode se transformar em perigosa e odiosa forma de discriminação. [...].

$[\ldots]$

Por tudo, razão assiste a Maria Lúcia Karam quando salienta que «a criação de novos tipos penais ou a maior severidade da repressão penal em relação a violências praticadas contra a mulher em nada podem contribuir para o reconhecimento e garantia de seus direitos, tampouco trazendo qualquer contribuição para que se avance na concretização da igualdade entre homens e mulheres e na construção de uma nova forma de convivência entre os sexos» (Yarochewsky 2014, s.p.).

Misturam-se naqueles argumentos sentidos de reflexão distintos: por um lado, a questão da igualdade de direitos e o princípio da isonomia no tratamento dos sujeitos sociais, e, por outro, a questão da crescente judicialização da vida social, ou seja, a resolução dos conflitos cotidianos através de mecanismos de julgamento e punição.

É plausível a tese de que a tendência para a regulação das relações sociais por meio de dispositivos normativos, e seu controle por mecanismos judiciais e do castigo, diminui a capacidade de mediação entre os indivíduos, e entre estes e as instituições, assumindo o poder público a tutela daqueles que vêm seus direitos ofendidos, e, portanto, não gerando práticas de assimilação de valores consolidados no convívio das diferenças e na diversidade de interesses. Todavia, menos evidente se apresenta a defesa de que a igualdade formal entre sujeitos possa ser afetada pela «discriminação positiva» instituída pela norma, sobretudo quando esta reconhece os limites do direito formal na resolução de desigualdades enraizadas nas representações e valores sociais.

É precisamente a constatação da existência de condições conjunturais expressas, por exemplo, nos dados estatísticos inicialmente referidos -, e históricas, de desigualdade de direitos reais fundada nas assimétricas relações de poder e nas diferenças de gênero que sustenta, segundo os defensores da Lei do Feminicídio, o princípio de «correção» das práticas sociais instituídas no âmbito de determinados grupos. Desta forma, estes grupos sistematicamente ofendem diretos e dominam pela violência outros grupos, não numa relação de competição de interesses, mas pela vulnerabilidade, discriminação e submissão em que se encontram e que tendem, no imaginário social, a tornar-se «naturais» ou inerentes à sua condição de existência. É, portanto, nessa perspectiva que é compreendido o feminicídio: o assassinato de mulheres, que não decorre de relações de conflito fundadas na competição de interesses ou de poder, mas da mera condição de ser mulher, 
entendida na sua situação histórica de subvaloração como ser humano. Segundo Mariana Paes, o debate pode ser articulado nos seguintes argumentos:

Ao contrário do que afirma Yarochewsky, não se trata de considerar a mulher como «sexo frágil», mas de reconhecer que mulheres e homens vivenciam, na vida privada, no âmbito doméstico e nas relações afetivas, situações de desigualdade que propiciam o uso da violência contra as mulheres. Assim, nas palavras de Leda Maria Hermann: «Reconhecer a condição hipossuficiente da mulher vítima de violência doméstica e/ou familiar não implica invalidar sua capacidade de reger a própria vida e administrar os próprios conflitos. Trata-se de garantir a intervenção estatal positiva, voltada à sua proteção e não à sua tutela.» Como argumenta Maria Berenice Dias, o próprio texto constitucional prevê tratamentos diferenciados para homens e mulheres. Essa diferenciação constitucional não tem como base diferenças biológicas, mas as desigualdades entre eles na divisão do trabalho. Ressalta a autora que: «O que se deve atentar não é à igualdade perante a lei, mas o direito à igualdade mediante a eliminação das desigualdades, o que impõe que se estabeleçam diferenciações específicas como única forma de dar efetividade ao preceito isonômico consagrado na Constituição» (Paes 2015, s.p.).

Trata-se de equacionar a questão da igualdade a partir de outra perspectiva: não de eliminar as desigualdades a partir da eliminação das diferenças, mas considerar que todos os indivíduos, sendo diferentes, têm o direito de usufruir e exercer todos os direitos humanos. O processo de conquista de acesso a esses direitos deverá percorrer caminhos tão diversos quanto diversas sejam as situações de desigualdade e de discriminação que historicamente afetam a diferença. Daí que a igualdade formal, vertida na norma jurídica, não tenha a capacidade de corrigir as diferenças, nem, por causa delas, garantir a igualdade de direitos. Haverá, e esse é o caso das mulheres, diferenças que não se situam no mesmo plano dicotômico; existem diferenças que são hierárquicas, que fixam as relações de poder e a classificação dos indivíduos, determinadas por valores e representações na ordem dos grupos dominantes.

\section{Diferença e hierarquia}

O feminicídio opera, no campo da hierarquia, entre grupos sociais concretos. Está subjacente a esse entendimento um pressuposto: no exercício da função patriarcal, os homens detêm o poder de determinar a conduta das categorias sociais nomeadas (mulheres, crianças e adolescentes), legitimados ou com a tolerância societal para punir o que se lhes apresenta como desvio.

Há que compreender quais as noções que consubstanciam a noção de insignificância e que fundamentam a desculpabilização das práticas violentas sobre a mulher em ambiente de relações intrafamiliares. 
Incidem sobre a mulher constrangimentos concretos, e amplamente disseminados, que tanto a condicionam nos mecanismos de relação em sociedade limitando-lhe direitos, impondo-lhe condutas, atribuindo-lhe funções -, como a tornam alvo de comportamentos discriminatórios e violentos que tendem a naturalizar-se tornando-os toleráveis. Quase dez anos após a sua entrada em vigor, os princípios e os valores expressos, por exemplo, na Lei Maria da Penha parece não terem sido incorporados de forma ampla nas formulações dos agentes judiciais. Também, os instrumentos jurídicos formulados não reverteram tendências, não alteraram contextos de violência, nomeadamente aqueles praticados em âmbito interfamiliar, conforme demonstram os dados estatísticos aqui apresentados. Esses valores e princípios vão persistindo nos entendimentos e códigos comportamentais assentes na desigualdade entre homens e mulheres e sustentados por práticas e valores do patriarcado dominante, ao ponto de se alegar a «insignificância» da conduta violenta do homem sobre a mulher.

É sobre essa resiliência que Maria Irene Ramalho reflete ao analisar a situação das mulheres na modernidade do capitalismo globalizado onde «elas não possuem seus próprios corpos e mentes, ou têm-nas apenas com grande risco, são sistematicamente silenciadas ou vitimadas nos meios de comunicação, continuam a ser consideradas menores e inferiores, e são muitas vezes tratadas como menos que lixo» ${ }^{5}(2013,25)$. Trata-se de abordagem a partir das categorias de análise «hierarquia» e "diferença», onde a autora se indaga sobre qual o momento de formulação desses modelos de discriminação, ou classificação «como chegamos a tal misógina exibição da diferença sexual que, pelo rebaixamento, descaracteriza e desumaniza as mulheres?» (Ramalho 2013, 27).

No percurso pela história das ideias e das representações, sobretudo expressas na literatura - do Livro de J, de Harold Bloom, passando pelos clássicos da literatura e filosofia gregas - Ramalho procura registrar os momentos em que se operaram mecanismos decisivos onde a «diferença» e a «hierarquia» determinaram a secundarização das mulheres no universo de referências fixado e dominado pelos homens.

Tal dedução parte da conviç̧ão de que em algum momento da história do Ocidente o «sexo» não era determinante da distinção entre homens e mulheres, nem fixaria evidentes estereótipos de papéis, capacidades e comportamento. Seguindo Page duBois (1982), em sua obra Centaurs and Amazons, Maria Irene Ramalho forma o entendimento de que essa diferenciação cultural emerge na Grécia a partir do século IV aC:

[a] emergência de hierarquia na Grécia antiga e a consolidação do que ainda é entendido hoje como o ordenamento adequado da sociedade humana: o homem no topo, em seguida, a fêmea, então a criança, o escravo, em seguida o bárbaro, e, finalmente, o animal (Ramalho 2013, 28-29).

Tradução livre da autora. 


\section{E constata que}

no século IV aC, houve uma mudança na história da cultura ocidental, uma mudança de uma anterior consciência mítica, literária, poética, baseada na analogia e polaridade tendo harmonia de raciocínio e sentimento, e preocupada com a condução correta de toda a vida da cidade, dando primazia aos logotipos e à racionalidade, centrando-se sobre o homem grego como o assunto da cidade e preocupada com uma elite (Ramalho 2013, 29).

Ou seja, existe mudança

quando a ideia de diferença - sexual, racial, e a diferença de espécies - foi entendida como a diferença que não tinha nada que ver com a infinita variedade, e tudo que ver com a hierarquização e estratificação. A nova ordenação social e cívica não foi baseada, como antes, em polaridade e analogia, mas, sim, na diferenciação hierárquica, subordinação e dominação (Ramalho 2013, 29).

Coloca-se a partir dessa racionalidade da ordem social, uma hierarquia sustentada na diferença. A questão central não é a diferença mas, sim, a centralidade do masculino na configuração do ordenamento social e político da polis grega: existiam os homens e os «não-homens». As mulheres fariam parte deste último grupo. Portanto, essa negação diferenciadora hierarquiza os papéis, determinando uma inferioridade, gerando um imaginário para o feminino a partir de uma impossibilidade, de uma limitação, que tende a naturalizar-se nas representações, ao ponto de condicionar a construção de um discurso próprio que se reflete até hoje. Ramalho refere que: «É por isso que, até hoje, teóricas feministas têm dificuldade em encontrar as palavras para falar da «mulher» fora do discurso hierárquico, hegemônico, filosófico, masculino» (Ramalho 2013, 31).

Tal como Maria Irene Ramalho, várias feministas, como Butler (1990), Cornell (1991), Braidotti (2001), têm vindo a empenhar-se na desconstrução desta manifestação filosófica dominante, que está presente desde a antiguidade, e que insiste em definir relações de dominação e subjugação, em que a mulher continua a ser definida, hierarquicamente, como o outro do mesmo, como o segundo sexo, como o sexo que não é. Forma-se, deste modo, um quadro de representações e práticas sociais onde se desculpabilizam os comportamentos violentos contra a mulher, quer eles se manifestem em violência simbólica, quer em violência física ou em restrição de direitos.

A vulnerabilidade da mulher não é consubstancial à sua posição jurídica dentro da família, nem à sua condição pessoal, mas à própria estrutura social fundada sobre as bases do domínio patriarcal. Trata-se do resultado de uma estratégia de dominação exercida pelo homem para manter a sua posição de poder. Nessa perspectiva, entende-se que a violência contra as mulheres evidencia o propósito de corrigir a transgressão (alguma conduta fora do papel atribuído) e garantir a continuidade de uma ordem tradicional de valores imposta por razões de gênero. 
As relações conjugais, ou de convivência familiar, são apenas o cenário privilegiado dessa violência, mas não o espaço exclusivo da multiplicidade de manifestações que se ocultam sob a etiqueta da violência de gênero. Essa abordagem, que reduz o fenômeno ao âmbito doméstico, é nefasta, dado que remete para o espaço da intimidade e do direito dos sujeitos com o qual a sociedade e as instituições têm ainda dificuldade de lidar.

Constituem-se, assim, padrões culturais tão assimilados que tendem a normalizar-se por se naturalizarem e se normatizarem como modelos de conduta. Daí que o problema dos maus-tratos contra as mulheres permaneça na privacidade, no silêncio do segredo, em um tabu que não deve sair do âmbito doméstico, e que o próprio grupo deve resolver sem a intervenção de terceiros, estranhos ao conflito (Laky 2011, 20-21).

Os estudos e as lutas feministas têm procurado superar a armadilha do argumento das diferenças situado nos pequenos espaços de relação, para expandir a reflexão para questões estruturantes do ordenamento social, e que envolve outras diferenças e desigualdades. Amelia Valcárcel, a partir de uma leitura das estratégias de luta feministas de tendência marxista, observa que para além da ideia de preexistência de um matriarcado primitivo, como algo que se extinguiu, acentuavam-se os efeitos da opressão do novo patriarcado, como o aparecimento das formas de exploração do homem pelo homem, que denominou como modos de produção capitalista. Essas circunstâncias exigiam o anúncio de um horizonte utópico: identificados os modos de produção e os respectivos períodos históricos, o advento do socialismo terminaria com a dinâmica da exploração do homem pelo homem de imediato e, com um pouco de ajuda, da mulher pelo homem (Laky 2011, 83-84).

Todo esse arcabouço explicativo tornou-se atrativo e útil para a teoria feminista, mas introduzia novo problema: «se se admite tal marco, a revolução das mulheres depende de uma revolução que termine com a libertação de todos os oprimidos» ${ }^{6}$ (Valcárcel 1995, 125). Assim expressa a autora:

\begin{abstract}
Sexo contra sexo ou classe contra classe, na verdade, as soluções situavam-se, com muitas matizes, entre ambos. É óbvio que para uma mulher é fácil pensar que a causa genérica da sua marginalização é o homem, de modo que, utilizando a doxa e a epistéme, havia que encontrar uma determinante que fosse além de uma mera aparência. $\mathrm{O}$ patriarcado era um sistema de dominação, o capitalismo de exploração e o patriarcado capitalista, uma improvisada síntese $(1995,126)$.
\end{abstract}

Colocava-se uma questão política: «contra qual lutar primeiro?» Se as lutas sociais impunham ao feminismo a sua terminologia, os seus problemas e a sua agenda política, também condicionavam as suas soluções e marcavam os limites do discurso e o nível das polêmicas possíveis. 
Abriam-se, assim, vertentes nas abordagens e nas lutas encetadas pelo feminismo. Por um lado, o feminismo que reivindicava a igualdade de direitos e oportunidades no pressuposto da existência de uma desigualdade estrutural discriminatória, mas não subentendia a distinção dos sujeitos segundo o gênero. Por outro lado, o feminismo que sustentava a diferença parecia estar a deslocar a sua base de teorização de um campo neutro e assexuado - de luta por um universo de igualdade entre todos os indivíduos baseado em um projeto social e político claro - para uma estrutura conceitual fundada na diferença socialmente construída entre homens e mulheres.

Esse impasse conceitual levanta a questão, se o feminismo é uma política ou uma ética. Valcárcel afirma que é necessário o aprofundamento das teorias de emancipação feminina para compreender e sustentar essas mudanças, mas não crê «necessária uma teoria política que as legitime: o feminismo é um movimento político» (Valcárcel 1995,131). É também nessa perspectiva que Ramalho analisa Rosi Braidotti $(2001,395)$ :

mas a eliminação total de diferenças, inclusive a diferença sexual, implica o desaparecimento do concreto, os seres humanos social e historicamente situados, e suas legítimas lutas e aspirações, no caso em apreço, o desaparecimento de mulheres concretas em uma sociedade longe de ser livre das formas mais crassas de misoginia e opressão sexual. Reconhecer a diferença sexual significa, portanto, de acordo com Braidotti, reconhecer as mulheres como livres, independentes e seres humanos autônomos, em pé de igualdade com os homens, portanto, prontas para lutar e reivindicar seus direitos, não importa quanto o ambiente é hostil (Ramalho 2013, 37-38).

A categoria de análise «diferença», que, por algum tempo - pelo menos enquanto o debate de situava no hemisfério norte ocidental -, parecia dar conta da análise e dos processos de superação das desigualdades de diversos tipos sexuais, raciais, religiosos -, deixou de ser tão eficaz quando as distintas situações das mulheres, em distintas condições sociais, em distintos lugares do mundo eram, também elas, diferentes.

A abordagem de gênero, ao integrar esse «feminismo da diferença», vem colocar o foco não na mera distinção segundo o sexo, mas na valoração diferenciada dos papéis e das entidades desempenhadas por homens e mulheres. Passouse a questionar a diferente valorização, não apenas econômica, quer da mulher, quer de suas atividades, tradicional e socialmente atribuídas, em comparação com outras desempenhadas pelos homens. É esse princípio de reconhecimento das diferenças que leva a perspectiva feminista a compreender o fenômeno da violência doméstica segundo uma configuração assimétrica (Laky 2011, 92).

É a noção de assimetria na utilização da dominação-exploração que potencia o poder masculino, tornando-o transversal a todas as relações sociais, sendo, portanto, objetivo e substancial e formalizando-se em estruturas hierarquizadas, em objetos e no senso comum. Nesse sentido, a hierarquia nas relações de poder, 
entre superiores e inferiores, entre aqueles que podem e os que não podem, prende-se à diferença para se legitimar as desigualdades, naturalizando-as ao ponto de submeter, oprimir, violentar e assassinar o outro.

O conjunto daquelas noções, produzidas no âmbito dos estudos feministas, ainda que tenham vindo a constituir-se como alertas e esclarecimentos relevantes que informam a agenda política, não têm tido capilaridade decisiva nas representações sociais, tanto no empoderamento das mulheres de se colocarem como sujeitos de direitos, como na reversão dos valores assimilados pelos homens, sobretudo no âmbito das relações familiares. Tal constatação evidencia-se, por exemplo, nos desdobramentos da Lei Maria da Penha, que, pouco anos após a sua aplicação, não conseguiu colocar-se como mudança de paradigma a partir dos valores das lutas feministas e dos direitos humanos.

As iniciativas legislativas, um pouco por todo mundo, têm compreendido aquela diferença imposta pela hierarquia como um fator determinante da discriminação e das práticas de submissão violenta da mulher. Entretanto, estabelecer um tipo penal específico para a punição, sobretudo, dos ofensores do direito à vida da mulher, considerando que ela é motivada por razões de diferença de gênero ou ódio expresso, é a forma de a sociedade, escondida na forma de Estado, se demitir de agir incisivamente. Assim, o Estado ao omitir-se também se demite da aprovação de políticas que permitam a reversão dos mecanismos que impõem a hierarquia e a diferença entre homens e mulheres, expiando a sua culpa institucional nos indivíduos que eventualmente consegue julgar e condenar, mas sem enfrentar a ideologia que lhe subjaz: o patriarcado.

No entanto, a punição exemplar, ainda que individual, cria fatores de dissuasão de condutas e comportamento, inibindo práticas individuais, mas não desconstrói as representações sociais assimiladas. Daí a dificuldade de enfrentar o feminicídio em Ciudad Juárez, no México, e em tantos lugares do mundo, uma vez que as práticas violentas ocultam-se no anonimato do coletivo dos agressores, que são, ao mesmo tempo, indivíduos que agem no âmbito do poder assimétrico fixado pela hierarquia de dominação, e o Estado que se demite de esclarecer e investigar situando-se na mesma ordem de dominação.

\section{Referências bibliográficas}

Agatón, Isabel. 2013. «El «feminicidio» se puede prevenir y se debe evitar». Mujeres en Red - El Periódico Feminista. Disponível no endereço http: / / www.mujeresenred.net/ spip.php?article2097 [consultado em 3.04.2016].

Braidotti, Rosi. 2001. «Becoming-Woman: Rethinking the Positivity of Difference». In Feminists Consequences: Theory for the New Century, editado por Elisabeth Bronfen e Misha Kavka, 381-413. Nova Iorque: Columbia University Press. DOI: https:/ / doi. org / 10.7312/ bron11704-014

Butler, Judith. 1990. Gender Trouble: Feminism and the Subversion of Identity. Nova Iorque: Routledge. 
Cameron, Deborah e Elizabeth Frazer. 1987. The Lust To Kill. Nova Iorque: New York University Press.

Cornell, Drucilla. 1991. Beyond Accommodation: Ethical Feminism, Deconstruction and the Law. Nova Iorque: Routledge.

duBois, Page. 1982. Centaurs and Amazons. Women and the Pre-History of the Great Chain of Being. Ann Arbor, MI: The University of Michigan Press.

Espósito, Carlos. 2011. Marcela Lagarde y la invención de la categoría 'feminicidio'. Blog Aquiescencia, 2.05.2011. Disponível no endereço http:/ / aquiescencia.net/2011/ 05/02 / marcela-lagarde-y-la-invencion-de-la-categoria-feminicidio [consultado em 3.04.2016].

Laky, Tania. 2011. «O pacto de segredo: a palavra é de prata e o silêncio é de ouro - simetria/assimetria de gênero no âmbito da violência entre homens e mulheres". Tese de Doutoramento, Programa de Estudos Pós-Graduados de Ciências Sociais, Pontifícia Universidade Católica de São Paulo.

Paes, Mariana Armond Dias. 2015. «Inclusão do feminicídio no Código Penal é uma questão de igualdade e gênero», Blog Consultor Jurídico, 10.01.2015. Disponível no endereço http: / / www.conjur.com.br / 2015-jan-10/ mariana-paes-feminicidio-questaoigualdade-genero\# author [consultado em 2.04.2016].

Ramalho, Maria Irene. 2013. «Difference and Hierarchy Revisited by Feminism». Revista Anglo Saxonica, Ser. III, N. 6: 21-45. Disponível no endereço http:/ / repositorio. ul.pt/ bitstream / 10451 / 23795 / 1 / ASaxoIII-N6_2_Difference\%20and\%20Hierarchy\%20Revisited.pdf [consultado em 3.04.2016].

Russell, E.H. Diana e Jill Radford. 1992. Femicide: the politics of woman killing. New York: Twain. Disponível no endereço http:/ / www.dianarussell.com/f/femicde(small). pdf [consultado em 2.04.2016].

Valcárcel, Amelia. 1995. «¿Es el feminismo una teoría política o una ética?» Debate Feminista, Año 6, vol. 12: 122-140.

Waiselfisz, Julio Jacobo. 2015. Mapa da violência 2015: homicídio de mulheres no Brasil. Brasília DF: ONU Mulheres, OPAS/OMS, SEPM, FLACSO Brasil. Disponível no endereço http:/ / www.mapadaviolencia.org.br/mapa2015_mulheres.php [consultado em 2.04.2016].

Yarochewsky, Leonardo Isaac. 2014. Feminicídio é um retrocesso na busca pela igualdade e no combate à discriminação. Blog Consultor Jurídico, 26.12.2014 Disponível no endereço http: / / www.conjur.com.br/ 2014-dez-26/leonardo-yarochewsky-feminicidioretrocesso-busca-igualdade?utm_source=dlvr.it\&utm_medium=facebook\# author [consultado em 2.04.2016].

Tania Teixeira Laky de Sousa. Doutora em Serviço Social e Ciências Sociais; Mestre em Direito pela Pontifícia Universidade Católica de São Paulo, Brasil; Coordenadora da Comissão da Violência Contra a Mulher da OAB-SP; Membro do Observatório Latino-Americano de Política Criminal do IBBCRIM; Menção Honrosa do Prémio Capes 2013. Publicações: «O Pacto de Segredo: Gênero e Violência entre Homens e Mulheres - a palavra é de prata e o silêncio é de ouro» (Editora Prismas, 2014) e «Tráfico Internacional de Mulheres: nova face de uma velha escravidão» (Editora Prismas, 2012).

Artigo recebido a 13 de abril de 2016 e aceite para publicação a 20 de setembro de 2016. 